\title{
ĐÁNH GIÁ SAU MỘT NĂM THỰC HIỆN TỤ̉ CHỦ CỦA CÁC TRƯờnG ĐẠi HỌC THUỘC BỘ CÔNG THƯƠNG
}

\author{
PHẠM NGÔ THÙY NINH \\ Vụ Phát triển nguông nhân lực, Bộ Công Thương; \\ ninhpnt@moit.gov.vn
}

\begin{abstract}
Trao quyền tự chủ cho các trường đại học $(Đ H)$ là xu thế chung trong cải cách giáo dục ĐH ở Việt Nam. Chính sách này nhằm hướng đến việc sử dụng có hiệu quả hơn các nguồn lực của các trường ĐH trước tác động của thị trường và yêu cầu xã hội. Trong thời gian qua, việc thí điểm cơ chế tự chủ tại các trường $Đ H$ công lập ở Việt Nam đã được triển khai thực hiện và đạt được một số kết quả nổi bật. Đối với các trường ĐH thuộc Bộ Công Thương, ngay sau khi Chính phủ ban hành Nghị quyết số 77/2014/NQ-CP ngày 24/10/2014 (gọi tắt là Nghị quyết 77), Bộ đã sớm triển khai tới các cơ sở đào tạo ĐH thuộc Bộ, có nguyện vọng tự chủ tiến hành xây dựng Đề án thí điểm đổi mới cơ chế hoạt động. Năm 2015 là năm ghi dâu ấn về đổi mới cơ chế trong hoạt động quản lý đào tạo của Bộ Công Thương, với 3 trường trực thuộc và 1 trường thuộc Bộ đã được Chính phủ ra Quyết định phê duyệt Đề án tự chủ, tuy nhiên để phát huy hiệu quả cơ chế này cần tiếp tục đổi mới mạnh mẽ hơn nữa...

Bài viết này bàn luận về thực hiện thí điểm cơ chế tự chủ của các trường ĐH thuộc Bộ Công Thương, đánh giá kết quả sau một năm, từ đó đề xuất một số giải pháp nhằm tiếp tục thực hiện có hiệu quả trong giai đoạn tiếp theo.
\end{abstract}

Keywords. Thí điểm cơ chế tự chủ, các trường ĐH thuộc Bộ Công Thương

Việc thực hiện quyền tự chủ là một trong những giải pháp quan trọng, để phát triển giáo dục ĐH ở Việt Nam. Vấn đề tự chủ của các trường ĐH đã được quy định tại Điều 60 Luật Giáo dục 2005, Điều 32 Luật Giáo dục ĐH 2012, sau đó tiếp tục được cụ thể hóa trong Điều lệ trường ĐH năm 2014 và Nghị định 16/2015/NĐ-CP ngày 14/2/2015 của Chính phủ quy định cơ chế tự chủ của đơn vị sự nghiệp công lập. Từ năm 2014, nước ta bắt đầu triển khai thí điểm trao quyền tự chủ toàn diện cho các trường Nghị quyết 77 . Theo đó, các trường được quyết định mục tiêu, chiến lược và kế hoạch phát triển; quyết định về tổ chức bộ máy, phát triển đội ngũ giảng viên, cán bộ quản lý trên cơ sở chiến lược và quy hoạch phát triển nhà trường; thu - chi tài chính, đầu tư phát triển dựa trên các điều kiện đảm bảo chất lượng đào tạo. Nghị quyết 77 là chìa khóa mở ra cánh cửa tự chủ tương đối rộng đối với các cơ sở giáo dục ĐH công lập trong các lĩnh vực: đào tạo và nghiên cứu khoa học; tổ chức bộ máy, nhân sự; tài chính, đầu tư...

Bộ Công Thương có 3 trường trực thuộc và 1 trường thuộc Bộ đã được Chính phủ ra Quyết định phê duyệt Đề án thí điểm cơ chế tự chủ. Đó là các trường: ĐH Công nghiệp Thành phố Hồ Chí Minh (viết tắt là IUH) ${ }^{1}$, ĐH Công nghiệp Thực phẩm Thành phố Hồ Chí Minh (viết tắt là HUFI) ${ }^{2}$, ĐH Điện lực (viết tắt là EPU) ${ }^{3}$ và ĐH Công nghiệp Dệt may Hà Nội (viết tắt là HICT) ${ }^{4}$. Riêng với HICT được Chính phủ phê duyệt mô hình tự chủ đặc biệt, theo đó Trường hoàn toàn độc lập, tự chủ trong quản lý, không trực thuộc một Bộ chủ quản nào sau khi tự chủ (chỉ chịu sự quản lý nhà nước về giáo dục $\mathrm{OH}$ của Bộ Giáo dục và Đào tạo, quản lý hành chính theo lãnh thổ của Ủy ban nhân dân Thành phố Hà Nội; Bộ Công Thương có trách nhiệm chỉ định Chủ tịch Hội đồng trường nhiệm kỳ đầu tiên và quyết định công nhận Hiệu trưởng).

\section{TÌNH HÌNH THỰC HIỆN TỬ CHỦ THEO NGHỊ QUYÉT 77 VÀ KẾT QUẢ CỦA NĂM ĐẦU TIÊN}

Triển khai Đề án thí điểm tự chủ, Bộ Công Thương hướng dẫn các trường xây dựng kế hoạch thực hiện tự chủ năm đầu tiên với ba nhiệm vụ trọng tâm: xây dựng, hoàn thiện khung pháp lý cho hoạt động của trường theo mức độ tự chủ mới; nâng cao chất lượng giáo dục $Đ H$ thông qua kiểm định, đánh giá chất

\footnotetext{
${ }^{1}$ Quyết định số 901/QĐ-TTg ngày 23/6/2015 của Thủ tướng Chính phủ

${ }^{2}$ Quyết định số 902/QĐ-TTg ngày 23/6/2015 của Thủ tướng Chính phủ

${ }^{3}$ Quyết định số $1508 / \mathrm{Q} Đ-T T g$ ngày 01/9/2015 của Thủ tướng Chính phủ

${ }^{4}$ Quyết định số 769/QĐ-TTg ngày 04/6/2015 của Thủ tướng Chính phủ
} 
lượng; quản lý thu chi hiệu quả tạo tiền đề xây dựng năng lực tài chính vững mạnh. Sau một năm thực hiện thí điểm, các trường đã đạt được một số kết quả bước đầu đáng ghi nhận theo đúng kế hoạch nhiệm vụ đã đề ra.

\subsection{Về đào tạo và nghiên cúu khoa học}

- Với quyền tự chủ trong mở ngành đào tạo: Hiệu trưởng nhà trường ra quyết định mở ngành tuân thủ các quy định hiện hành của Bộ Giáo dục và Đào tạo. Trong năm qua các trường đã xây dựng các quy định, quy trình về mở ngành, chuyên ngành cho trình độ $Đ H$ và thạc sĩ và mở mới hoặc đang chuẩn bị mở mới các ngành nghề kỹ thuật và công nghệ nhằm đáp ứng nhu cầu xã hội.

Bảng 1- Ngành mở mới trong năm học 2015- 2016 của 4 trường tự chủ ${ }^{5}$

\begin{tabular}{|c|c|c|}
\hline Trường & Ngành mở mới do Bộ GDĐT quyết định & Ngành mở mới do Trường tự quyết định \\
\hline IUH & & $\begin{array}{c}\text { Tiến sĩ } 1 \text { ngành, thạc sỹ } 4 \text { ngành, đại học } 15 \\
\text { ngành }\end{array}$ \\
\hline HUFI & & $\begin{array}{c}\text { Thạc sĩ } 2 \text { ngành, đại học } 5 \text { ngành, cao đẳng } 1 \\
\text { ngành }\end{array}$ \\
\hline EPU & Tiến sĩ 1 ngành & Đại học 1 ngành, liên thông TC-ĐH 2 ngành \\
\hline HICT & Đại học 3 ngành & \\
\hline
\end{tabular}

Có hai trường hợp mở ngành do Bộ Giáo dục và Đào tạo ra quyết định. Lý do: HICT mở mới các ngành đào tạo trình độ $\mathrm{DH}$ trước đây Trường chưa đủ điều kiện do là trường cao đẳng; $\mathrm{EPU}$ mở ngành Quản lý Năng lượng trình độ tiến sĩ là ngành mới chưa nằm trong danh mục ngành đào tạo. Các trường hợp mở ngành khác do hiệu trưởng ra quyết định, thủ tục hành chính đã giảm đáng kể. Đối với các trường hợp phải trình Bộ Giáo dục và Đào tạo, việc thực hiện vẫn thuận lợi, nhanh chóng hơn do Trường được tự thành lập Hội đồng thẩm định chương trình đào tạo.

- Các trường tự xác định chỉ tiêu tuyển sinh trên cơ sở các tiêu chí, quy định hiện hành của Bộ Giáo dục và Đào tạo. Phương án tuyển sinh dựa trên nguyên tắc chất lượng đầu vào đảm bảo yêu cầu và phù hợp từng hệ, ngành đào tạo, được công bố công khai trên các phương tiên thông tin đại chúng. Phương thức tuyển sinh là sử dụng kết quả của kỳ thi trung học phổ thông quốc gia và (hoặc) kết quả điểm trung bình học tập của 3 năm học trung học phổ thông (học bạ) làm cơ sở xét tuyển đại học và cao đẳng chính quy. Các trường cũng đã giảm chỉ tiêu cao đẳng để đảm bảo lộ trình đến 2020 sẽ dừng tuyển sinh trình độ này, tập trung nâng cao chất lượng đào tạo $\mathrm{DH}$ và bậc cao (thạc sĩ, tiến sĩ) theo đúng chủ trương của Chính phủ và Bộ Công Thương. Công tác tuyển sinh $H$, cao đẳng chính quy năm học 2016-2017 đã hoàn thành tốt và đạt được kết quả cả về số lượng và chất lượng như năm học 2015-2016. Kết quả tuyển sinh 2 năm qua cho thấy, mặc dù các trường đều có mức thu học phí cao hơn các trường công lập khác (mức thu học phí riêng thực hiện theo Đề án tự chủ được phê duyệt), nhưng vẫn đạt kết quả tuyển sinh tốt. Điều đó thể hiện uy tín, chất lượng đào tạo và thương hiệu của các trường trong hệ thống giáo dục hiện nay. Đây là một trong những điều kiện quan trọng để có thể thực hiện tự chủ thành công trong thời gian tới.

- Các trường đã và đang tiếp tục hoàn chỉnh chuẩn đầu ra của các chuyên ngành đào tạo và công khai cam kết chuẩn đầu ra trên trang thông tin điện tử của Trường. HUFI đã điều chỉnh và bổ sung một số chuẩn đầu ra về ngoại ngữ, công nghệ thông tin, kỹ năng mềm để hướng tới đảm bảo chất lượng nhân lực toàn diện hơn, đáp ứng yêu cầu xã hội.

- Báo cáo của 4 trường cho thấy, 100\% các trường đã tiến hành tự đánh giá chất lượng giáo dục đào tạo theo các quy định của Bộ Giáo dục và Đào tạo về quy trình và tiêu chuẩn đánh giá chất lượng giáo dục trường đại học (đánh giá trong), trên cơ sở đó điều chỉnh các nguồn lực và quá trình thực hiện của từng trường, nhằm đạt tiêu chuẩn chất lượng giáo dục do Tổ chức kiểm định chất lượng giáo dục đánh giá (đánh giá ngoài). Bên cạnh việc tiến hành đánh giá ngoài theo tiêu chuẩn quốc gia, năm 2016, IUH đang triển khai tự đánh giá 6 ngành chương trình đào tạo bậc đại học theo Bộ tiêu chuẩn ABET (Accreditation Board for Engineering and Technology) và 23 chương trình đào tạo bậc đại học theo Bộ tiêu chuẩn AUN-

\footnotetext{
${ }^{5}$ Nguồn số liệu: Báo cáo một năm thực hiện tự chủ của các trường, tháng 9/2016
} 
QA (ASEAN University Network - Quality Assurance); HUFI cũng đang xây dựng chương trình đào tạo để chuẩn bị đánh giá theo tiêu chuẩn $\mathrm{AUN}-\mathrm{QA}$. Dự kiến thời gian kiểm định quốc tế của hai trường trên hoàn tất vào năm 2020, 2023.

Bảng 2- Kết quả tuyển sinh năm học 2015- 2016, 2016-2017 hệ sau đại học, đại học, cao đẳng của các trường tự chủ thuộc Bộ Công Thương ${ }^{6}$

ĐVT: sinh viên

\begin{tabular}{|c|c|c|c|c|}
\hline Trường/năm & Kế hoạch tuyển sinh & Đã nhập học & \% đạt KH & Ghi chú \\
\hline $\begin{array}{l}\text { IUH } \\
\text { Năm học 2015-2016 } \\
\text { Năm học 2016-2017 }\end{array}$ & $\begin{array}{l}8.500 \\
6.900\end{array}$ & $\begin{array}{l}8.903 \\
6.626\end{array}$ & $\begin{array}{l}105 \% \\
96 \%\end{array}$ & $\begin{array}{l}\text { Điểm chuẩn: } 19-20.75 \\
\text { Điểm chuẩn: } 18-21.5\end{array}$ \\
\hline $\begin{array}{l}\text { HUFI } \\
\text { Năm học 2015-2016 } \\
\text { Năm học 2016-2017 }\end{array}$ & $\begin{array}{l}3.760 \\
2.900\end{array}$ & $\begin{array}{l}3.452 \\
2.900\end{array}$ & $\begin{array}{l}92 \% \\
100 \%\end{array}$ & \\
\hline $\begin{array}{l}\text { EPU } \\
\text { Năm học 2015-2016 } \\
\text { Năm học 2016-2017 }\end{array}$ & $\begin{array}{l}3.050 \\
3.050\end{array}$ & $\begin{array}{l}3.230 \\
2.815\end{array}$ & $\begin{array}{l}106 \% \\
92 \%\end{array}$ & \\
\hline $\begin{array}{l}\text { HICT } \\
\text { Năm học 2015-2016 } \\
\text { Năm học 2016-2017 }\end{array}$ & $\begin{array}{l}2.810 \\
1.410 \\
\end{array}$ & $\begin{array}{l}2.134 \\
1.500 \\
\end{array}$ & $\begin{array}{c}76 \% \\
106 \% \\
\end{array}$ & \\
\hline
\end{tabular}

Bảng 3- Một số số liệu thống kê về các hoạt động đảm bảo chất lượng của các trường ĐH tự chủ thuộc Bộ Công Thương năm 2015- $2016^{7}$

\begin{tabular}{|c|c|c|c|c|c|c|}
\hline \multirow{2}{*}{ Stt } & \multirow{2}{*}{ Nội dung } & \multirow{2}{*}{ Đv tính } & \multicolumn{4}{|c|}{ Kết quả/Số lượng } \\
\hline & & & IUH & HUFI & EPU & HICT \\
\hline $\mathrm{I}$ & Kiểm định chất lượng & & & & & \\
\hline 1 & Đánh giá trong theo chuẩn quốc gia & Tiêu chí đạt & $61 / 61$ & $57 / 61$ & $56 / 61$ & $53 / 55$ \\
\hline 2 & Đánh giá ngoài trong theo chuẩn quốc gia & Tiêu chí đạt & $49 / 61$ & $\begin{array}{l}\text { Đang } \\
\text { thẩm } \\
\text { định }\end{array}$ & $\begin{array}{l}\text { Đang } \\
\text { thẩm } \\
\text { định }\end{array}$ & $\begin{array}{l}\text { Chưa } \\
\text { thực } \\
\text { hiện }\end{array}$ \\
\hline 3 & $\begin{array}{l}\text { Đánh giá theo tiêu chuẩn ABET, AUN- } \\
\text { QA, khác }\end{array}$ & Ngành & 29 & 0 & 0 & 0 \\
\hline II & Khảo thí & & & & & \\
\hline 1 & $\begin{array}{l}\text { Số môn học được xây dựng bộ đề } \\
\text { thi/ngân hàng câu hỏi thi }\end{array}$ & môn học & 243 & 665 & 61 & 188 \\
\hline 2 & $\begin{array}{l}\text { Số môn học được xây dựng trọng số nội } \\
\text { dung và cấu trúc đề thi }\end{array}$ & môn học & & 665 & 33 & 176 \\
\hline III & Điều tra, khảo sát & & & & & \\
\hline 1 & $\begin{array}{l}\text { Số cuộc điều tra khảo sát người học về } \\
\text { môn học }\end{array}$ & cuộc & & 2 & 6 & 15 \\
\hline 2 & $\begin{array}{l}\text { Số cuộc điều tra khảo sát người học về } \\
\text { hoạt động giảng dạy }\end{array}$ & cuộc & & 2 & 6 & 286 \\
\hline 3 & $\begin{array}{l}\text { Cuộc điều tra sinh viên chuẩn bị tốt } \\
\text { nghiệp về CTGD và các hoạt động/dịch } \\
\text { vụ hồ trợ sinh viên }\end{array}$ & cuộc & & 2 & 1 & 9 \\
\hline 4 & $\begin{array}{l}\text { Cuộc điều tra khảo sát cựu sinh viên về } \\
\text { việc làm }\end{array}$ & cuộc & & 2 & 1 & 12 \\
\hline 5 & $\begin{array}{l}\text { Cuộc khảo sát ý kiến phản hồi của nhà sử } \\
\text { dụng lao động về sinh viên tốt nghiệp }\end{array}$ & cuộc & 39.480 & 0 & 0 & 5 \\
\hline IV & Tỷ lệ giảng viên tự đánh giá & $\%$ & $66 \%$ & $100 \%$ & $\mathbf{0}$ & 100 \\
\hline
\end{tabular}

${ }^{6}$ Nguồn số liệu: Báo cáo một năm thực hiện tự chủ của các trường, tháng 9/2016

${ }^{7}$ Nguồn số liệu: Báo cáo một năm thực hiện tự chủ của các trường, tháng 9/2016 
- Các trường đã, đang xây dựng lại quy trình về thủ tục thực hiện liên kết đào tạo trong và ngoài nước với quyền được quyết định liên kết trong chỉ tiêu đào tạo trường tự xác định, trên cơ sở điều kiện quy định. Với quyền này, các trường đã thực sự chủ động, tích cực, đa dạng hóa các hoạt động đào tạo liên kết, hỗ trợ đào tạo tại các địa phương và liên kết đào tạo nước ngoài theo thế mạnh của từng trường, như:

+ IUH đang triển khai 2 chương trình liên kết đào tạo trình độ thạc sĩ với Trường ĐH Soongsil SSU, Hàn Quốc (ngành Quản trị kinh doanh) và Trường ĐH Liege - ULg, Vương quốc Bỉ (ngành Khoa học và Quản lý Môi trường).

+ HUFI đang triển khai liên kết đào tạo với 7 cơ sở đào tạo tại 7 tỉnh thành trong nước với quy mô khoảng 2.000 sinh viên.

+ EPU đào tạo theo hợp đồng với Điện lực Thượng Hải, liên kết với các công ty Nhật Bản đào tạo theo chuyên đề Điện hạt nhân, liên kết đào tạo trình độ cao đẳng Hệ thống điện với Học viện Chisholm Úc.

+ HICT đào tạo theo đơn đặt hàng với 11 doanh nghiệp và tập đoàn trong nước cho 2.010 học viên về Quản lý sản xuất, may mẫu rải chuyền, sản xuất veston... Các doanh nghiệp hỗ trợ các trường về sản phẩm học tập, trang thiết bị thực tập để sinh viên được thực hành trên trang thiết bị thực tế và sản phẩm thực do đó gắn đào tạo với thực tiễn. Trường phối hợp với Tổng cục Dạy nghề tổ chức ôn luyện thi tay nghề ASEAN cho đoàn thí sinh Lào, mở ra cơ hội hợp tác lâu dài trong đào tạo nguồn nhân lực dệt may cho Lào.

- Để tập trung đầu tư hơn cho nghiên cứu khoa học và nâng cao chất lượng giảng viên, các trường đã thể chế hóa quyền tự chủ trong nghiên cứu khoa học thể hiện ở Quy chế chi tiêu nội bộ (xây dựng định mức chi cho công tác nghiên cứu khoa học, biên soạn giáo trình, mức thưởng các bài báo khoa học...), quy định thời gian dành cho nghiên cứu khoa học đối với mỗi giảng viên; xây dựng quy trình xét duyệt đề tài nghiên cứu khoa học cấp Trường; ban hành Quy định về biên soạn, thẩm định và xuất bản giáo trình phục vụ công tác giảng dạy và nghiên cứu khoa học... Theo các báo cáo kết quả thực hiện, trường có bước tiến rõ rệt về nghiên cứu khoa học so với trước khi thực hiện tự chủ là IUH: công bố khoa học năm học 2015-2016 tăng 23,6\% so với năm học 2014-2015; lực lượng giảng viên tham gia nghiên cứu khoa học tăng 7,4\%; doanh thu nghiên cứu khoa học tăng 25,8\% (năm 2014 đạt 4,75 tỷ đồng, năm 2015 đạt 6,41 tỷ đồng).

- Về chuyển giao công nghệ, liên doanh, liên kết: Thời gian qua, các trường cũng đã ký kết các hợp đồng phối hợp nghiên cứu, phối hợp chế tạo và sản xuất với các đối tác là doanh nghiệp trong nước. (IUH ký hợp đồng với Công ty Môi trường đô thị, Công ty Dịch vụ khai thác thủy lợi, Tổng Công ty Cơ khí Sài Gòn; chuyển giao sản phẩm nghiên cứu của đề tài nhà nước thuộc chương trình năng lượng KC05.02/2011-2015 cho Công ty Lương thực tỉnh Tiền Giang. HICT đã chuyển giao công nghệ Lean thành công cho Công ty Cổ phần May Nam Định giúp tăng năng suất và chất lượng sản phẩm).

Bảng 4\&5 - Kết quả nghiên cứu khoa học và chuyển giao công nghệ của các trường trước và sau khi thực hiện tự chủe

- Năm học 2014-2015

\begin{tabular}{|c|c|c|c|c|c|c|c|c|}
\hline \multirow[b]{2}{*}{ Trường } & \multicolumn{5}{|c|}{ Số công trình $\mathrm{KH}$ công bố từ kết quả đề tài nc } & \multirow{2}{*}{$\begin{array}{l}\text { Số hợp } \\
\text { đồng } \\
\text { CGCN từ } \\
\text { kết quả } \\
\text { nc }\end{array}$} & \multirow{2}{*}{$\begin{array}{l}\text { Tỷ lệ chi } \\
\text { cho } \\
\text { NCKH/ } \\
\text { tồng chi } \\
(\%)\end{array}$} & \multirow[b]{2}{*}{$\begin{array}{l}\text { Tỷ lệ thu từ } \\
\text { NCKH \& } \\
\text { CGCN trên } \\
\text { tổng thu (\%) }\end{array}$} \\
\hline & $\begin{array}{l}\text { Phát } \\
\text { minh } \\
\text { sáng } \\
\text { chế }\end{array}$ & $\begin{array}{l}\text { Số hợp } \\
\text { dồng } \\
\text { CGCN }\end{array}$ & $\begin{array}{l}\text { Bài } \\
\text { đăng } \\
\text { trong } \\
\text { nước }\end{array}$ & $\begin{array}{l}\text { Bài đăng quốc tế } \\
\text { thuộc hệ thống ISI } \\
\quad \& \text { scopus }\end{array}$ & $\begin{array}{l}\text { Bài đăng } \\
\text { Hội thảo } \\
\text { quốc tế }\end{array}$ & & & \\
\hline IUH & 1 & 57 & 115 & 68 & 75 & 2 & 2 & 1,34 \\
\hline HUFI & 0 & 0 & 4 & & & 1 & 0,59 & 0.74 \\
\hline EPU & & & 33 & & & & 0.38 & 1,64 \\
\hline HICT & & & & & & & & \\
\hline
\end{tabular}

${ }^{8}$ Nguồn số liệu: Báo cáo một năm thực hiện tự chủ của các trường, tháng 9/2016 
- Năm học 2015-2016

\begin{tabular}{|c|c|c|c|c|c|c|c|c|}
\hline \multirow[b]{2}{*}{ Trường } & \multicolumn{5}{|c|}{ Số công trình $\mathrm{KH}$ công bố từ kết quả đề tài nc } & \multirow{2}{*}{$\begin{array}{l}\text { Số hợp } \\
\text { đồng } \\
\text { CGCN từ } \\
\text { kết quả } \\
\text { nc }\end{array}$} & \multirow{2}{*}{$\begin{array}{l}\text { Tỷ lệ chi } \\
\text { cho } \\
\text { NCKH/ } \\
\text { tổng chi } \\
(\%)\end{array}$} & \multirow[b]{2}{*}{$\begin{array}{l}\text { Tỷ lệ thu từ } \\
\text { NCKH \& } \\
\text { CGCN trên } \\
\text { tổng thu }(\%)\end{array}$} \\
\hline & $\begin{array}{l}\text { Phát } \\
\text { minh } \\
\text { sáng } \\
\text { chế }\end{array}$ & $\begin{array}{l}\text { Số hợp } \\
\text { đồng } \\
\text { CGCN }\end{array}$ & $\begin{array}{l}\text { Bài } \\
\text { đăng } \\
\text { trong } \\
\text { nước }\end{array}$ & $\begin{array}{l}\text { Bài đăng quốc tế } \\
\text { thuộc hệ thống ISI } \\
\text { \& scopus }\end{array}$ & $\begin{array}{l}\text { Bài đăng } \\
\text { Hội thảo } \\
\text { quốc tế }\end{array}$ & & & \\
\hline IUH & 0 & 61 & 188 & 40 & 111 & 11 & 5,1 & 2,1 \\
\hline HUFI & 0 & 0 & 100 & 10 & & 4 & 0,61 & 2,11 \\
\hline EPU & 1 & & 16 & & & & 0.24 & 1,57 \\
\hline HICT & 9 & 1 & & & & 1 & 2 & 3 \\
\hline
\end{tabular}

Qua phân tích số liệu trên từ nguồn báo cáo của các trường cho thấy, IUH và HICT là hai trường có sự thay đổi rõ nét về kết quả nghiên cứu khoa học và chuyển giao công nghệ. Các trường đã chú trọng đầu tư cho nghiên cứu khoa học và việc ứng dụng kết quả nghiên cứu vào thực tế sản xuất kinh doanh, đã bước cải thiện tỷ lệ thu từ nghiên cứu khoa học và chuyển giao công nghệ trên tổng số thu của trường theo chiều hướng tăng. Sự thay đổi ở các chỉ số này chưa rõ nét ở các trường HUFI và EPU nhưng một số chỉ tiêu khác có tăng như số bài báo, số hợp đồng chuyển giao công nghệ từ kết quả nghiên cứu. Điều đó cho thấy cơ chế tự chủ đã bước đầu tác động tới kết quả nghiên cứu khoa học và chuyển giao công nghệ. Tuy nhiên, các trường cần tập trung phát huy hơn nữa thế mạnh của nghiên cứu khoa học làm cơ sở nâng cao chất lượng đào tạo và vị thế, uy tín của trường trong "thị trường" cung cấp dịch vụ đào tạo.

\subsection{Về tổ chức bộ máy, nhân sư}

HICT đã thành lập Hội đồng trường và đang trong quá trình hoàn thiện quy chế hoạt động, để Hội đồng trường phát huy được vai trò quản lý một cách hiệu quả với quyền lực thực chất nhất sau khi đi vào hoạt động từ tháng 4/2016. IUH đã được Bộ phê duyệt danh sách Hội đồng trường. Các trường HUFI và EPU sau thời gian ổn định về nhân sự lãnh đạo đang nghiên cứu, xây dựng phương án thành lập Hội đồng trường để trình Bộ xem xét phê duyệt.

Các trường đã ban hành các quy chế quản lý nội bộ phù hợp, để đưa các hoạt động của Nhà trường đi vào ổn định theo hướng tự chủ toàn diện hơn, như: Quy chế làm việc, Quy chế tuyển dụng, tập sự và bổ nhiệm ngạch viên chức, Quy chế tổ chức hoạt động của Phân hiệu trường, Quy chế chi tiêu nội, Quy chế tổ chức tiếp công dân... Một số quy định, quy chế còn lại đang trong quá trình chỉnh sửa, cập nhật cho phù hợp với cơ chế hoạt động mới theo Đề án thí điểm cơ chế tự chủ.

Bước đầu sắp xếp, phân công lao động phù hợp với vị trí việc làm, tiếp tục kiện toàn bộ máy tổ chức cho hiệu quả hơn. Các trường cũng tổ chức tuyển dụng giảng viên có học hàm, học vị cao, đáp ứng yêu cầu nâng cao chất lượng đội ngũ giảng dạy $\mathrm{ÐH}$, sau ĐH trong thời gian tới. Công tác tuyển dụng thực hiện đúng quy trình, quy định và công khai, minh bạch. Cán bộ quản lý trẻ, có trình độ, năng lực được bổ sung vào Quy hoạch cán bộ quản lý các cấp của Trường trong giai đoạn 2016 - 2021.

\subsection{Về tài chính}

Theo Đề án được Chính phủ phê duyệt, các trường tự xây dựng phương án thu học phí và ban hành quy định thu học phí. Mức thu học phí chương trình chính quy, đại trà từ năm học 2014-2015 có tăng nhưng chưa tới mức trần đề án đã được duyệt. Riêng Trường Đại học Công nghiệp Dệt may thu theo khung học phí Chính phủ ban hành tại Nghị định 86/2015/NĐ-CP.

Như đã nêu trên, mặc dù quy mô đào tạo giảm dần do các trường tập trung đầu tư cho chất lượng đào tạo và giảm tuyển sinh trình độ cao đẳng, nhưng kết quả tuyển sinh đại học vẫn khá tốt. Với mức thu học phí tăng, số thu học phí năm học 2015-2016 ở hầu hêt các trường đều tăng ${ }^{9}$ nên tổng thu học phí, lệ phí của 4 trường đã tăng lên khoảng 9\% so với năm học 2014-2015.

\footnotetext{
${ }^{9}$ Xem biểu số 1- So sánh số thu học phí, lệ phí trước và sau khi thực hiện tự chủ
} 


\section{CỦA CÁC TRUỜNG ĐẠI HỌC THUỘC BỘ CÔNG THU'ƠNG}

Bảng 6- Mức thu học phí bình quân của các trường tự chủ năm học 2014-2015 10

\begin{tabular}{|l|c|c|c|}
\hline \multirow{2}{*}{ Trường } & Mức thu học phí (triệu đồng/1 tháng/1 sinh viên) \\
\cline { 2 - 4 } & Cao đẳng & Đại học & Thạc sĩ \\
\hline UIH & 1,00 & 1,25 & 1,875 \\
\hline HUFI & 0,976 & 1,2 & Chưa đào tạo \\
\hline EPU & 0,93 & 1,17 & 1,95 \\
\hline HICT & 0,76 & Chưa đào tạo & Chưa đào tạo \\
\hline
\end{tabular}

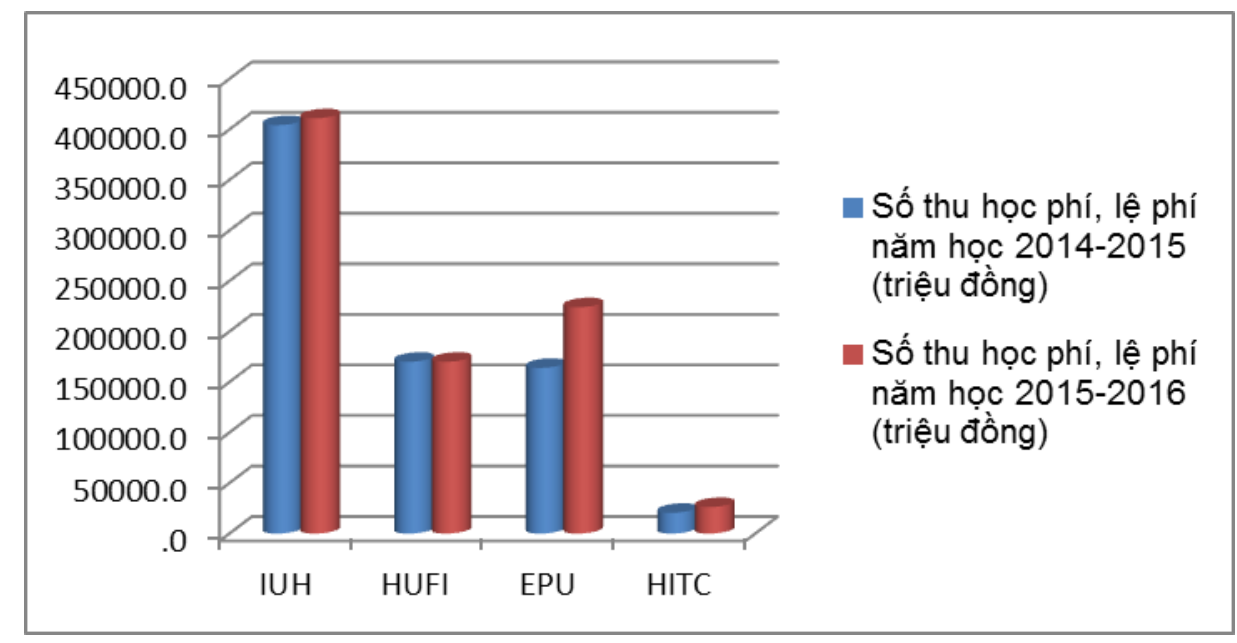

Biểu đồ 1 - So sánh số thu học phí, lệ phí trước và sau khi thực hiện tự chủ ${ }^{11}$ Nguồn: Báo cáo của các trường tháng 9/2016

Do chi phí đào tạo đã được tính tương đối đủ vào học phí hơn so với các năm trước, nên trường không phải thu thêm nhiều khoản thu khác. Mức thu của các khoản thu sự nghiệp khác ngoài học phí này cũng được các trường xây dựng theo tiêu chí: bù đắp chi phí, tích lũy hợp lý. Vì vậy, tổng số thu sự nghiệp khác của cả 4 trường không tăng mà giảm $3 \%$. Do tập trung vào nhiệm vụ đào tạo, tổng thu từ sản xuất kinh doanh dịch vụ của các trường cũng giảm $12 \%$. Từ trước khi thực hiện tự chủ, ngân sách nhà nước cấp cho chi thường xuyên cũng gần như không bố trí ở các trường này. Tuy nhiên, nguồn thu từ ngân sách cấp cho năm học 2015-2016 lại tăng khoảng 38\%, đó là vốn đối ứng cho các dự án ODA, ngân sách cấp bù thực hiện miễn giảm học phí cho các đối tượng chính sách, và ngân sách hỗ trợ cho nghiên cứu khoa học, thực hiện một số nhiệm vụ đào tạo quốc tế... Xét về tổng thể, số thu từ tất cả các nguồn của cả 4 trường tăng chỉ khoảng $6 \%$, nhưng cơ cấu nguồn thu có sự dịch chuyển theo đúng hướng, là phát huy vai trò sứ mệnh đào tạo nguồn nhân lực của các trường trong điều kiện tự chủ tài chính.

Thực hiện một trong các nhiệm vụ trọng tâm của năm là "quản lý thu chi hiệu quả tạo tiền đề xây dựng năng lực tài chính vững mạnh", việc chi tiêu do các trường tự quyết, tự kiểm soát đã thể hiện những dấu hiệu tích cực với những thay đổi ban đầu trong cơ cấu chi như sau:

\footnotetext{
${ }^{10}$ Nguồn số liệu: Báo cáo một năm thực hiện tự chủ của các trường, tháng 9/2016

${ }^{11}$ Nguồn số liệu: Báo cáo một năm thực hiện tự chủ của các trường, tháng 9/2016
} 


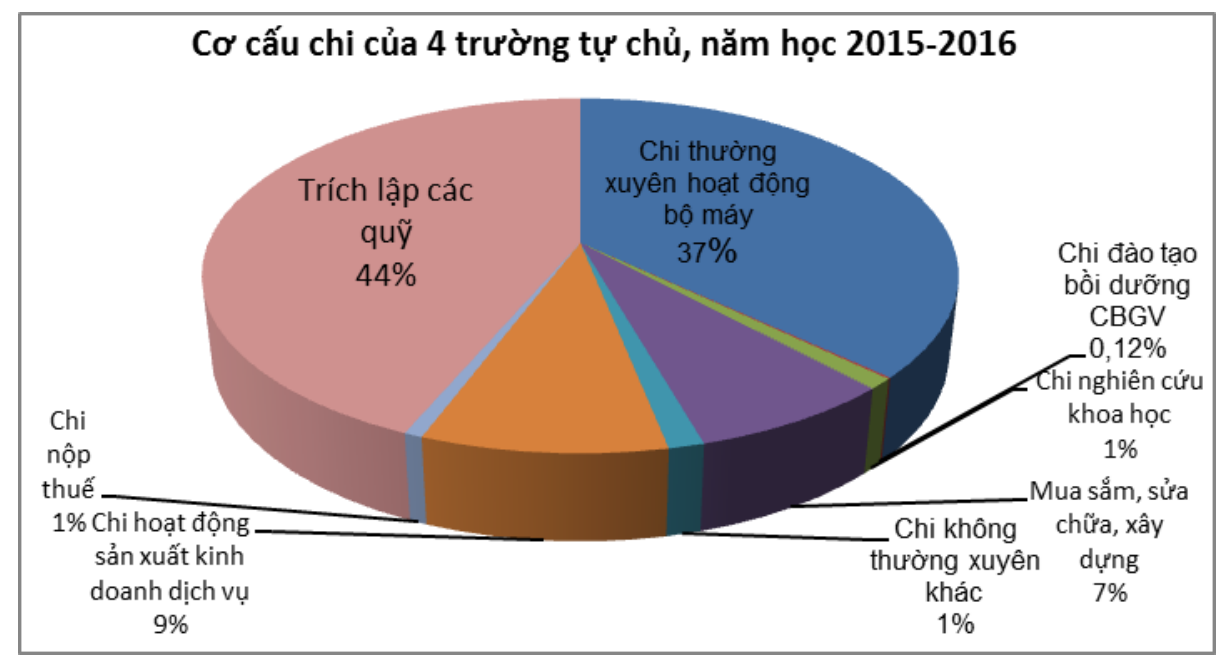

Biểu đồ 2- Cơ cấu chi của 4 trường tự chủ năm học 2015-2016

Nếu trong năm học 2014-2015, chi thường xuyên hoạt động bộ máy của 4 trường chiếm khoảng 42\% thì sau khi được tự chủ về tổ chức, bộ máy hoạt động, biên chể và tài chính, tỷ lệ chi thường xuyên cho hoạt động bộ máy của các trường giảm xuống $5 \%$, do đó tỷ lệ trích lập các quỹ tăng lên từ $40 \%$ năm 2014-2015 lên 44\% năm học 2015-2016. Ngoài lý do giảm chi bộ máy trong khi nguồn thu học phí tăng lên, tỷ lệ trích lập quỹ tăng còn do nguyên nhân các trường được sử dụng tiền lãi ngân hàng để lập quỹ học bổng cho sinh viên. Ngoài ra, một dấu hiệu nữa, tuy nhỏ nhưng đã thể hiện sự chuyển biến tích cực trong cơ cấu chi là tỷ lệ chi cho nghiên cứu khoa học đã tăng từ $0,2 \%$ lên gần $1 \%$ trong năm qua. Trong số 4 trường, HICT là trường có sự gia tăng đột biến về chi cho nghiên cứu khoa học với tỷ lệ $2 \%$. Tại Nhật Bản, tỷ lệ này được chia theo các loại hình nghiên cứu, theo đó, tỷ lệ \% kinh phí năm 2005 cho nghiên cứu cơ bản, nghiên cứu ứng dụng và nghiên cứu phát triển của các trường đào tạo $\mathrm{DH}$ và cao học trên tổng chi tương ứng là: $55,1 \% ; 35,8 \% ; 9,1 \%{ }^{13}$. Ví dụ trên cho thấy tỷ lệ chi này của các trường cần được tiếp tục cải thiện trong các năm tới.

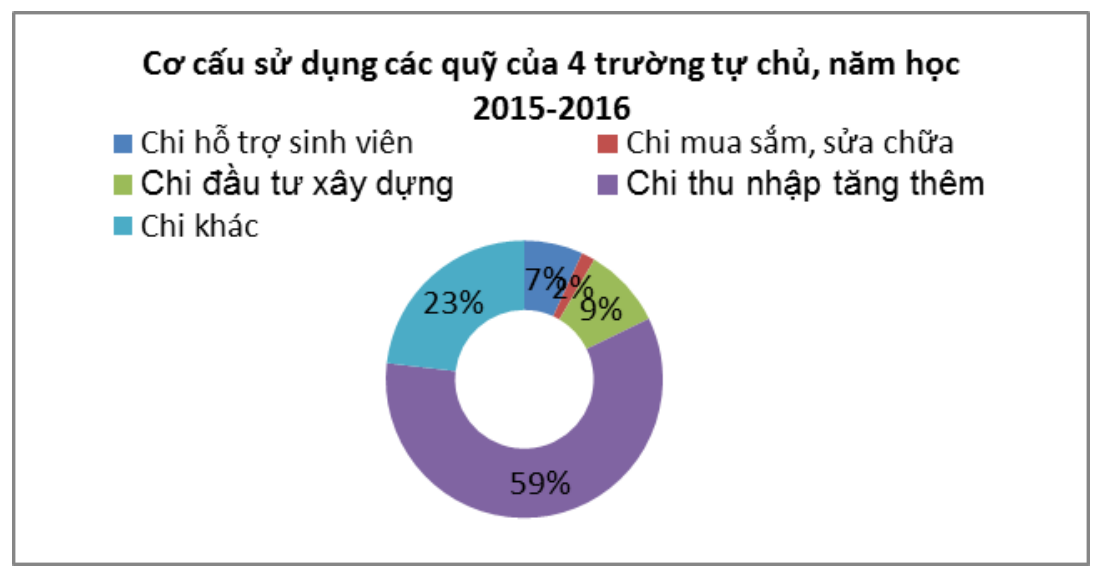

Biểu số 3- Cơ cấu sử dụng các quỹ của 4 trường tự chủ năm học 2015-2016 $6^{14}$

Về việc sử dụng các quỹ, năm học 2015-2016, có sự thay đổi rõ rệt về chi hỗ trợ sinh viên, tăng từ hơn $1 \%$ lên gần $7 \%$ với việc hỗ trợ các sinh viên nghèo vượt khó, học bổng cho sinh viên học giỏi, sinh viên có hoàn cảnh đặc biệt (khuyết tật, mồ côi...) và chi bù đắp chểnh lệch giữa số miễn giảm học phí

\footnotetext{
${ }^{12}$ Nguồn số liệu: Báo cáo một năm thực hiện tự chủ của các trường, tháng 9/2016

13 Tổ chức và quản lý đề tài nghiên cứu khoa học ở Nhật- Hồ Tú Bảo, Viện Khoa học và Công nghệ Việt Nam, website: http://www.jaist.ac.jp, truy cập ngày 02/2/2016

${ }^{14}$ Nguồn số liệu: Báo cáo một năm thực hiện tự chủ của các trường, tháng 9/2016
} 


\section{CỦA CÁC TRƯỜNG ĐẠI HỌC THUộC Bộ CÔNG THƯƠNG}

ngân sách cấp bù và mức chi (học phí) của trường. Thu nhập tăng thêm đã được điều chỉnh tăng theo Quy chế chi tiêu nội bộ, tỷ lệ chi thu nhập tăng thêm trong cơ cấu chi từ các quỹ tăng khoảng $12 \%$ so với năm trước, tính trên tổng quỹ của tất cả các trường.

Như vậy, việc chuyển dịch cơ cấu thu, chi của các trường năm qua thể hiện hướng đi tích cực của quản lý tài chính tự chủ theo đúng mục tiêu, nâng cao hiệu quả sử dụng nguồn lực đảm bảo chất lượng đào tạo.

\section{4. Đầu tư xây dụng co sở vật chất, trang thiết bị}

Với quyền tự chủ, các trường được tự cân đối nguồn thu và huy động từ các nguồn hợp pháp khác để tự quyết định các dự án đầu tư, mua sắm, sửa chữa nhằm mục tiêu nâng cao chất lượng đào tạo và theo mô hình các trường đại học tiên tiến trên thế giới. Trong năm học 2015-2016, từ nguồn thu hợp pháp, tổng số chi của các trường cho nhiệm vụ này tăng khoảng $60 \%$ so với năm trước nhưng từ quỹ phát triển hoạt động sự nghiệp, tổng số chi cho nhiệm vụ này của các trường giảm đi dẫn tới tỷ lệ chi không tăng so với năm trước. IUH đang tích lũy vốn cho dự án xây dựng cơ sở mới tại Quận 12 - TP. Hồ Chí Minh nên số chi trong năm tuy có tăng so với năm trước nhưng nhìn chung tổng số chi xây dựng, mua sắm của cả 4 trường có giảm đi đáng kể.

Riêng IUH trong năm học 2015-2016, đã chi đầu tư mua sắm các trang thiết bị phục vụ giảng dạy và học tập với kinh phí 30,475 tỷ đồng, tăng $62 \%$ so với năm 2014 ; chi 11,4 tỷ đồng để sửa chữa các phòng học, phòng thí nghiệm, thực hành, mua sắm trang thiết bị bàn ghế, tạo môi trường học tập, nghiên cứu khoa học cho sinh viên và giảng viên ${ }^{15}$.

Đối với các trường tự chủ phải tự đảm bảo chi thường xuyên và chi đầu tư, Chính phủ tạo điều kiện bố trí vốn vay ưu đãi từ các tổ chức quốc tế cho trường để đầu tư cơ sở vật chất, trang thiết bị hiện đại, làm cơ sở ban đầu cho việc thực hiện tự chủ được thuận lợi. Năm 2016, IUH được tham gia vào dự án đầu tư của Ngân hàng Thế giới với dự kiến được khoản vay ưu đãi 45 triệu USD. Dự án đang trong quá trình thẩm định. Đối với các trường còn lại, Bộ vẫn tích cực tìm kiếm các nguồn hỗ trợ bằng vốn hoặc kỹ thuật.

\subsection{Giám sát nội bộ và tụ chịu trách nhiệm}

Theo hướng dẫn của Bộ, các trường đã và đang xây dựng quy chế giám sát nội bộ, chống lạm dụng quyền tự chủ; quy định trách nhiệm công khai và giải trình với xã hội, với các bên liên quan về hoạt động và kết quả hoạt động của Trường. Đề nâng cao vai trò giám sát nội bộ, IUH đã thành lập Phòng Thanh tra - Pháp chế.

Tóm lại, sau một năm thực hiện tự chủ, với một số kết quả đạt được trên các mặt: đào tạo, nghiên cứu khoa học, tổ chức bộ máy, nhân sự, tài chính, đầu tư xây dựng, giám sát nội bộ và chịu trách nhiệm, các trường đang thể hiện những dấu hiệu chuyển biến tích cực theo đúng mục tiêu đổi mới là nhằm nâng cao chất lượng đào tạo và hiệu quả sử dụng nguồn lực.

\section{KHÓ KHĂN, VƯỚNG MẮC}

Bên cạnh các kết quả đạt được, việc thí điểm cơ chế tự chủ năm vừa qua của các trường ĐH cũng bộc lộc một số vướng mắc, khó khăn:

Thứ nhất, đến nay, ngoài Nghị quyết 77 và Nghị định 16/NĐ-CP của Chính phủ thì các văn bản hướng dẫn chi tiết hoặc quy định có liên quan khác chưa được chỉnh sửa, ban hành kịp thời, thống nhất, đồng bộ trong việc thực hiện giao quyền tự chủ. Điều này khiến các trường còn lúng túng, khi các quy định hiện hành giới hạn quyền tự chủ và chính các cơ quan quản lý nhà nước cũng vướng mắc khi kiểm tra, giám sát. Chẳng hạn:

- Chưa có văn bản quy định phân cấp và thẩm quyền chi tiết, rõ ràng đối với đơn vị tự chủ trong đầu tư, mua sắm tài sản. Các trường còn e ngại rằng việc họ tự ra quyết định vẫn là ngược với các quy định hiện hành và sẽ gặp khó khăn khi giải trình với các cơ quan kiểm tra, kiểm toán nhà nước...;

- Trường được chủ động xác định chỉ tiêu tuyển sinh, chủ động thu học phí để trang trải tất cả chi phí nhưng Thông tư số 32/2015/TT-BGDĐT ngày 16/12/2015 của Bộ Giáo dục và Đào tạo, quy định về việc xác định chỉ tiêu tuyển sinh đối với các cơ sở giáo dục đại học có hiệu lực thi hành kể từ ngày

\footnotetext{
${ }^{15}$ Nguồn: Báo cáo kết quả 01 năm thực hiện tự chủ của IUH
} 


\section{CỦA CÁC TRƯỜNG ĐẠI HỌC THUộC Bộ CÔNG THƯƠNG}

01/02/2016, lại giới hạn rất chặt về quy mô sinh viên có thể dẫn tới giảm nguồn thu học phí là nguồn chính để cân đối thu - chi; vay vốn;

- Các trường vẫn chưa được giao vốn và tài sản để chủ động trong liên doanh liên kết, hoặc thế chấp

- Các trường gặp vướng mắc với thủ tục miễn thuế đất tại địa phương, do văn bản chỉ quy định miễn thuế cho các đơn vị xã hội hóa (Nghị định 69/2008/NĐ-CP ngày 30/5/2008 của Chính phủ về chính sách khuyến khích xã hội hóa trong lĩnh vực giáo dục, dạy nghề) chứ chưa quy định cho các đơn vị tự chủ.

Thứ hai, mặc dù đã được hỗ trợ từ Chính phủ trong việc vay vốn $\mathrm{ODA}$, nhu cầu vốn đầu tư nâng cấp cơ sở vật chất, trang thiết bị, điều kiện học tập, giảng dạy, nghiên cứu khoa học... của các trường ĐH rất lớn, cần nguồn kinh phí hỗ trợ.

Thứ $\boldsymbol{b a}$, hệ thống văn bản quản lý, quy chế hoạt động trường phải sửa đổi nhiều, phương thức quản lý giáo dục tiên tiến chưa được áp dụng nhiều trong các cơ sở đào tạo công lập ở Việt Nam để các trường học hỏi, rút kinh nghiệm, trong khi, bản thân các trường còn hạn chế về trình độ và nhận thức của đội ngũ quản lý và nhân viên.

\section{MỘT SỐ GIẢI PHÁP VÀ KIẾN NGH!̣}

Năm học 2016-2017, là năm thứ hai thực hiện đề án thí điểm đổi mới cơ chế hoạt động của các trường theo hướng tự chủ. Trên cơ sở kết quả đạt được của năm học vừa qua, các trường tiếp tục thực hiện mục tiêu tự chủ với một số nội dung được gợi ý là nhiệm vụ kế hoạch cho năm 2017-2018 của các trường tự chủ là:

- Tiếp tục hoàn thiện khung pháp lý và áp dụng các phương thức quản lý tiên tiến;

- Đầu tư cho nghiên cứu khoa học và ứng dụng chuyển giao công nghệ;

- Tiếp tục tăng cường năng lực tài chính và nâng cao trách nhiệm giải trình.

Để khắc phục những khó khăn vướng mắc của các trường tự chủ trong năm qua và để đảm bảo các trường hoàn thành được các nhiệm vụ của năm học tới, một số giải pháp được đề xuất như sau:

- Khẩn trương hoàn thành việc thành lập Hội đồng trường ở các trường IUH, HUFI, EPU để quản lý các hoạt động của trường, đảm bảo quyền tự chủ đã được giao.

- Các trường xây dựng định mức kinh tế kỹ thuật cho từng dịch vụ đào tạo để làm căn cứ định giá dịch vự và xây dựng kế hoạch tài chính hằng năm, đồng thời làm cắn cứ cho việc giám sát nội bộ và giám sát, kiểm tra, đánh giá chất lượng dịch vụ của Bộ.

- Các trường nghiên cứu xây dựng, điều chỉnh bổ sung các quy định về trách nhiệm giải trình đối với các trường trong hoạt động quản lý đào tạo và hoạt động tài chính.

- Bộ Công Thương phân cấp quản lý đảm bảo quyền tự chủ và trách nhiệm xã hội đối với các trường của Bộ, theo đúng mức độ tự chủ đã được Chính phủ phê duyệt và trong khả năng phân quyền của Bộ. Việc phân cấp cần được có sự chỉ đạo thống nhất của Bộ tới các Vụ và có các văn bản hướng dẫn triệt để, đảm bảo hiệu lực và tính khả thi.

- Bộ Công Thương đẩy nhanh việc giao vốn, giao tài sản cho các trường; tiến tới cho áp dụng hạch toán theo mô hình doanh nghiệp và kêu gọi đầu tư trong nước, ngoài nước nhằm từng bước xã hội hóa cơ sở vật chất phục vụ đào tạo để phát triển trường.

- Bộ hỗ trợ các trường đây mạnh nghiên cứu khoa học và chuyển giao công nghệ bằng biện pháp phối hợp, trao đổi nghiên cứu giữa các trường $\mathrm{ÐH}$, cao đẳng và các viện nghiên cứu của $\mathrm{B}$ ộ, hoặc với các trường ở địa phương nơi trường đặt địa bàn; khai thác thế mạnh của từng trường qua việc hướng đề tài nghiên cứu đển giải quyết các vấn đề thực tế và cấp thiết trước mắt của các doanh nghiệp thuộc Bộ. Cách thực hiện: Bộ tổ chức những buổi họp giữa lãnh đạo tập đoàn, tổng công ty, công ty, các viện nghiên cứu và các trường để lấy ý kiến của họ về hướng nghiên cứu mới, về những vấn đề cần giải quyết trong thời gian trước mắt; sau đó có thể tổ chức đấu thầu hoặc đặt hàng các trường ĐH về những lĩnh vực mà họ chuyên sâu.

Ngoài ra, một số kiến nghị được đề xuất với các cơ quan chức năng như sau:

- Chính phủ, các Bộ, ngành liên quan xây dựng và ban hành các văn bản, quy định hướng dẫn cụ thể và thống nhất các nội dung tự chủ, các quyền tự chủ mà trường $\mathrm{ĐH}$ được thực hiện; về việc phân quyền, cơ chế kiểm tra, giám sát của các cơ quan quản lý nhà nước theo đó tập trung kiểm soát kết quả đầu ra; 


\section{CỦA CÁC TRƯỜNG ĐẠI HỌC THUộC Bộ CÔNG THƯƠNG}

- Có chính sách hỗ trợ cho các trường ĐH vay vốn ưu đãi từ các tổ chức, cá nhân trong nước và nước ngoài để đầu tư xây dựng, mua sắm thêm trang thiết bị, phòng học, phòng thí nghiệm, thực hành hiện đại, phục vụ yêu cầu học tập và nghiên cứu khoa học của giảng viên và sinh viên;

- Được hưởng uu đãi thuế và các chính sách ưu đãi như các đơn vị xã hội hóa theo Nghị định 69/2008/NĐ-CP của Chính phủ;

- Cho phép các trường được công nhận diện tích đất thuê trong việc xác định chỉ tiêu tuyển sinh hằng năm theo quy định của Bộ Giáo dục và Đào tạo, được tính số giảng viên ký hợp đồng khoán việc vào số lượng giảng viên cơ hữu của trường;

- Doanh nghiệp Việt Nam phần lớn là doanh nghiệp nhỏ và vừa, do vậy, việc sử dụng lao động chưa có sự đầu tư lâu dài nên việc kết gắn Nhà trường và doanh nghiệp gặp nhiều khó khăn, trong khi đó cơ chế hỗ trợ từ phía nhà nước còn thiếu. Vì thế, cần có những chính sách ưu đãi nhất định (hoặc chế tài) thích hợp để doanh nghiệp phối hợp chặt chẽ với trường trong việc nghiên cứu, đào tạo và việc làm cho sinh viên.

Trong tiến trình đổi mới giáo dục, việc quản trị của các trường ĐH theo hướng tự chủ nhằm nâng cao chất lượng đào tạo luôn là yêu cầu cấp thiết được đặt ra đối với các trường ĐH thuộc Bộ Công Thương nói riêng và các trường $\mathrm{ĐH}$ công lập nói chung. Nghị quyết 77 và Nghị định 16 đã ra đời với nhiều nội dung quy định mức độ tự chủ cao hơn, được kỳ vọng sẽ tạo ra chuyển biến tích cực và hiệu quả cho hoạt động quản lý của các đơn vị sự nghiệp đào tạo công lập. Với những kết quả đạt được năm qua của các trường thực hiện thí điểm đổi mới cơ chế hoạt động theo Nghị quyết 77 , có thể khẳng định việc hoàn thiện và chuyển đổi cơ chế quản lý các trường ĐH theo hướng tự chủ là xu thế phù hợp, tất yếu và mở ra cơ hội cho các trường hội nhập sâu rộng với các nước trong khu vực và thế giới.

\section{TÀI LIỆU THAM KHẢO}

1. Bộ Công Thương, (3/2016), Báo cáo kết quả thực hiện Nghị quyết 77/NQ-CP.

2. Bộ Công Thương, (9/2016), Báo cáo một năm thực hiện tự chủ.

3. Bộ Giáo dục và Đào tạo, (2016), Sự phát triển của hệ thống giáo dục ĐH, các giải pháp bảo đảm và nâng cao chất lượng đào tạo.

4. Các trường ĐH thuộc Bộ Công Thương, (2015), Kế hoạch hoạt động năm 2016.

5. Luật Giáo dục đại học số 08/2012/QH13, (2012).

6. Luật Giáo dục nghề nghiệp số 74/2014/QH13, (2014).

7. Nghị định số 16/2015/NĐ-CP ngày 14 tháng 2 năm 2015 của Chính phủ về việc quy định cơ chế tự chủ của đơn vị sự nghiệp công lập.

8. Nghị quyết số 77/NQ-CP ngày 24 tháng 10 năm 2014 của Chính phủ về thí điểm đổi mới cơ chế hoạt động đối với các cơ sở giáo dục ĐH công lập giai đoạn 2014-2017

9. Nhóm đối thoại giáo dục Việt Nam, (2015), "Khuyến nghị về đại học Việt Nam", www.vietnamnet.vn/giaoduc.

10. Phạm Thị Lan Phượng, (2015), "Dịch chuyển cơ chế quản trị giáo dục đại học trên toàn cầu và suy ngẫm về Việt Nam”, Tạp chí Khoa học ĐH Sư phạm, Thành phố Hồ Chí Minh.

11. Quyết định số 901/QĐ-TTg ngày 23 tháng 6 năm 2015 của Chính phủ về việc phê duyệt đề án thí điểm đổi mới cơ chế hoạt động của Trường ĐH Công nghiệp Thực phẩm Thành phố Hồ Chí Minh.

12. Quyết định số 902/QĐ-TTg ngày 23 tháng 6 năm 2015 của Chính phủ về việc phê duyệt đề án thí điểm đổi mới cơ chế hoạt động của Trường ĐH Công nghiệp Thành phố Hồ Chí Minh.

13. Quyết định số 1508/QĐ-TTg ngày 01 tháng 9 năm 2015 của Chính phủ về việc phê duyệt đề án thí điểm đổi mới cơ chế hoạt động của Trường ĐH Điện lực. 


\section{CỦA CÁC TRƯỜ ĐẠI HỌC THUỘC BỘ CÔNG THƯƠNG}

14. Trường ĐH Công nghiệp thành phố Hồ Chí Minh, (2015), Đề án thí điểm đổi mới cơ chế hoạt động theo Nghị quyết 77/NQ-CP.

15. Trường ĐH Công nghiệp Thành phố Hồ Chí Minh, (2016), Báo cáo tình hình thực hiện thí điểm đổi mới cơ chế hoạt động theo Nghị quyết 77/NQ-CP.

16. Trường ĐH Công nghiệp Thực phẩm Thành phố Hồ Chí Minh, (2015), Đề án thí điểm đổi mới cơ chế hoạt động theo Nghị quyết 77/NQ-CP.

17. Trường ĐH Công nghiệp Thực phẩm Thành phố Hồ Chí Minh, (2016), Báo cáo tình hình thực hiện thí điểm đổi mới cơ chế hoạt động theo Nghị quyết 77/NQ-CP.

18. Trường ĐH Điện lực, (2015), Đề án thí điểm đổi mới cơ chế hoạt động theo Nghị quyết 77/NQ-CP.

19. Trường ĐH Điện lực, (2016), Báo cáo tình hình thực hiện thí điểm đổi mới cơ chế hoạt động theo Nghị quyết 77/NQ-CP.

20. Wold bank, 2013, SABER overview, What, Why and How of the Systems Approach for Better Education Results... 